\title{
MODELING THE PROCESS OF APPLYING ANTI-CRISIS MANAGEMENT IN THE SYSTEM OF ENSURING FINANCIAL SECURITY OF THE ENTERPRISE
}

\author{
Oleksandr SYLKIN ${ }^{\circledR 1}$, Myroslav KRYSHTANOVYCH ${ }^{(2)}$, Andryi ZACHEPA ${ }^{\circledR 3}$, \\ Sofiia BILOUS ${ }^{(1)}{ }^{4}$, Anna KRASKO ${ }^{5}{ }^{5}$
}

\author{
${ }^{1,3}$ Faculty of Media Communications and Entrepreneurship, Ukrainian Academy of Printing, Lviv, Ukraine \\ ${ }^{2}$ Department of Pedagogy and Social Management, Lviv Polytechnic National University, Lviv, Ukraine \\ ${ }^{4,5}$ Faculty of Geography, Ivan Franko National University of Lviv, Lviv, Ukraine \\ E-mails: ${ }^{1}$ bestmaktorn@gmail.com (correspondingauthor); ${ }^{2}$ sylkin_os@ukr.net; \\ 3marina_1901@ukr.net; ${ }^{3}$ biloisSofi@i.ua; ${ }^{5}$ anna.khovalko@i.ua
}

Received 20 August 2019; accepted 14 October 2019

\begin{abstract}
The methodological approach to the application of anti-crisis management in the system of ensuring financial security of the enterprise, unlike the existing ones, summarizes and systematizes the theoretical and methodological features of determining the main stages of anti-crisis management, based on the use of functional modelling methodology and graphical description of processes (IDEF0), significantly increases the ability enterprises adapt to a changing market environment, increase competitiveness and ensure to be stable in financial activities. A complex diagram of the IDEF0 model of applying the anti-crisis management in the process of ensuring the financial security of the enterprise is proposed. It includes input, control, output, mechanism. As a result, a decomposition of the first and the second level context diagrams of the IDEF0 model of anti-crisis management application in the process of ensuring the financial security of the enterprise was formed, which includes, in addition to input, control, output and mechanism, information about the progress of subprocesses and directives for their regulation.
\end{abstract}

Keywords: financial security, anti-crisis management, enterprise, model, system.

JEL Classifications: D21, D81, L62, G32.

\section{Introduction}

Crisis is no longer a new concept for the global economy. For entrepreneurs, this is the biggest threat that can lead to the bankruptcy. The emergence of crisis phenomena in the economy led to the development of anti-crisis actions. The increase in new large-scale financial crises (the financial crisis in Mexico in 1995; the big crisis in the countries of Southeast Asia in 1997; the global financial and economic crisis of 2008 and others) only confirmed the fact of the need to develop new anti-crisis measures.

Today in the field of management, the concept of "anticrisis management" has evolved and is a constant continuous process at the enterprise. But the crisis can not always strike a blow to the entire enterprise, mainly it can affect one of its links: financial, marketing, administrative, production and technological and the like. So, the most vulnerable place is the financial component of the enterprise. This led to the study of anti-crisis management in the system of ensuring the financial security of the enterprise.

The financial security of the enterprise is such a financial condition in which an appropriate level of security is ensured in the long term and there is the ability to counteract external and internal threats. One of the key conditions for ensuring the financial security of the enterprise is not only a high degree of harmony, successful coordination of financial interests, but also the ability to withstand threats to the financial system, which, in turn, can lead to a crisis.

Copyright @ 2019 The Authors. Published by VGTU Press.

This is an Open Access article distributed under the terms of the Creative Commons Attribution License (http://creativecommons.org/licenses/by/4.0/), which permits unrestricted use, distribution, and reproduction in any medium, provided the original author and source are credited.. 
Extemporaneous applying of anti-crisis management is very difficult and costly. Anti-crisis management is a certain sequence of management efforts, should be carried out in stages. We believe that this kind of process from a technological point of view should be presented just in the form of a certain sequence of stages and procedures that have both direct and feedback connections. That is why, given this factor, we set ourselves the goal of determining at what stage of activity it is necessary to apply anti-crisis management. This question can be answered by developing an appropriate model of the process of applying anti-crisis management in the system of ensuring financial security of the enterprise, which will bring us closer to improving the functioning and increasing the effective system of financial security in general.

\section{Literature review}

The one of founder of the study of the concept of "anticrisis management of the enterprise" is R. Barton (1993).

A sufficient amount of attention has been paid to the study of the problems of applying the anti-crisis management in the world. For example, I. Schwartz (2008) in her work explored the possibilities of creating a mechanism to ensure the effectiveness of anti-crisis management at the enterprises by systematizing, modelling existing relationships in the research object, as well as dominant factors influencing the effectiveness of these processes.

An interesting study is B. Zhou (2016), which investigated the strategy of managing the finances of an enterprise in the aftermath of the global financial crisis. Where I considered such crisis-specific features as bankruptcy and management capabilities that will overcome this.

An interesting study was carried out by K. Golovach (2016), who used the Logit model in her work, based on the unambiguous interpretation of the results and the absence of the so-called "zones of uncertainty", which makes it possible to predict crisis phenomena and make anti-crisis decisions in the context of binary choice.

A. Abdulaziz (2016) made a significant contribution to the development of strategic directions for the introduction of anti-crisis management for enterprises by determining the dynamics of opportunities and threats.

In 2018, V. Gavrilenko (2018), who determined the scientific paradigm of accounting and analytical support for enterprise anti-crisis management, made a significant contribution to the development of the organization of the issue of accounting and analytical support for enterprise anticrisis management, consists in identifying, determination and tracking the development of internal and external crisis threats for the formation of the information base for the adoption of anti-crisis decisions by integrating the incoming, internal and outgoing information flows of accounting, controlling, analysis in the accounting modelling system.
A good one is a study of the general provisions of security as such and its management, presented in $\mathrm{Wu}$ Y. and Meng F. (2019).

A study of the essence of financial security of an enterprise is devoted to the works of A. Lynenko and V. Konyev (2017) and P. Hryhoruk et al. (2019).

A large number of scientific papers have been devoted to the study of the problems of ensuring the financial security of the enterprise, among which the following should be highlighted: A. Malik (2015) (conducted a thorough study of the evolution of scientific views on the nature of the financial security of the enterprise); E. Kartuzov (2012) (formed the main categories that must be attributed to the conceptual apparatus of the financial security of the enterprise); A. Arefieva and T. Kuzenko (2009) (considered financial security from the perspective of six approaches).

Unfortunately, the number of threats that can affect enterprises is only growing, and often their influence can be observed precisely in the financial sector, therefore ensuring an appropriate level of financial security is one of the most important scientific topics among scientists, in particular: A. Smovkina (2014) general features of the impact of threats to financial security with threats to economic security; A. Marchenko (2014) allocated directions to increase the level of financial security, ranging from mega-economic to nano-economic; A. Plastun (2007) investigated the development of the financial security system of business entities in the sphere of material production.

A financial crisis can result from both internal and external threats. To prevent and overcome it, they apply the anti-crisis management system, which, after the financial crisis in 2008, gained high relevance in research among leading scientists, in particular N. Ershova (2009) investigated diagnostics in the anti-crisis management system; V. Shary (2006) investigated anti-crisis technologies as a mechanism for implementing the goals of public administration; A. Pogrebnyak (2016) formed the conceptual provisions for the formation of the anti-crisis management mechanism.

Paying tribute to the scientific contribution of the leading scientists of the world, it should be noted that today the issue of modelling the process of using anti-crisis management in the system of ensuring financial security of the enterprise remains relevant.

\section{Research model}

To implement this task, we use the methodology of functional modelling and graphical description of processes (IDEF0). Its feature among other models is the emphasis on objects, which allows a better understanding of the subjectivity of the research area. It should be noted that according to IDEF0 methodology, the objects of functional modelling and structural analysis are just organizational and economic systems. 
IDEF0, as a standard, was developed in 1981 as part of a wide industrial automation program, which was designated ICAM (Integrated Computer Aided Manufacturing). The IDEF family of standards took its designation from the names of this program (IDEF = ICAM DEFinition). In the process of practical implementation, ICAM program participants were faced with the need to develop new methods for analysing the processes of relationships in industrial systems. Moreover, in addition to the improved set of functions for describing business processes, one of the requirements for the new standard was the availability of an effective interaction methodology within the framework of the "analyst-specialist". In other words, the new method was supposed to provide group work on the creation of the model, with the direct participation of all analysts and specialists involved in the project.

As a result of the search for appropriate solutions, a functional modelling methodology IDEF0 was born. Since 1981, some minor changes have been made to the IDEF0 standard, mainly of a restrictive and recommendatory nature, its most recent version was released in December 1993 by the US National Institute of Standards and Technology (NIST).

The formalization of such a process as anti-crisis management in the system of ensuring the financial security of the enterprise should compensate for the existing shortcomings caused by the inability to solve them using exclusively quantitative methods of analysis. If threats and problems arising at the enterprise are considered in a strict logical sequence, then this, in turn, makes it possible to combine formal and heuristic methods in the process of preparing and making appropriate decisions. Thus, the quality and effectiveness of these solutions is achieved.

As for the creation of any other functional model, the IDEF0 model should have the corresponding initial data, which serve as a basic platform for creating a model of the process of applying anti-crisis management to ensure the financial security of the enterprise.

The key structural components of the source data for the formation of a functional model of the process of applying anti-crisis management in the system of ensuring financial security of the enterprise are the following elements are presented in Table 1.

The process of applying the anti-crisis management in the system of ensuring the financial security of the enterprise should include such a stinginess of stages that will make it possible directly turn all input material and information flows into flows that will have completely different properties at the output.

So the process of applying anti-crisis management in the system of ensuring the financial security of the enterprise will take place in accordance with the directives for managing its sub-processes. Such directives are formed on the basis of the main objective of the enterprise. In our case, this is counteraction to internal and external threats and crisis processes.
Table 1. Key structural components of the source data for the formation of a functional model of the application of anti-crisis management in the system of ensuring financial security of the enterprise (source: developed by author)

\begin{tabular}{|l|l|}
\hline \multicolumn{1}{|c|}{$\begin{array}{c}\text { Structural } \\
\text { component }\end{array}$} & \multicolumn{1}{c|}{ Characteristic } \\
\hline $\begin{array}{l}\text { Purpose of } \\
\text { modeling }\end{array}$ & $\begin{array}{l}\text { The purpose of modeling is to develop } \\
\text { a functional model IDEF0 to support } \\
\text { the adoption of anti-crisis management } \\
\text { decisions in the process of ensuring the } \\
\text { financial security of the enterprise }\end{array}$ \\
\hline Point of view & $\begin{array}{l}\text { The subjects of financial security, the } \\
\text { activity of which provides for the } \\
\text { development and implementation of anti- } \\
\text { crisis management decisions to bring the } \\
\text { enterprise out of crisis and ensure its safety }\end{array}$ \\
\hline $\begin{array}{l}\text { The target } \\
\text { audience of the } \\
\text { model }\end{array}$ & $\begin{array}{l}\text { The target audience of the model is the } \\
\text { subjects of financial security, who must } \\
\text { own information technologies for the } \\
\text { development and adoption of optimal } \\
\text { anti-crisis management decisions aimed at } \\
\text { countering crisis processes }\end{array}$ \\
\hline $\begin{array}{l}\text { Functional } \\
\text { model context }\end{array}$ & $\begin{array}{l}\text { A list of functions and diagram objects of } \\
\text { the IDEF0 functional model }\end{array}$ \\
\hline $\begin{array}{l}\text { Modeling } \\
\text { technology }\end{array}$ & $\begin{array}{l}\text { Methodology of functional modeling } \\
\text { IDEF0 }\end{array}$ \\
\hline $\begin{array}{l}\text { Modeling } \\
\text { software }\end{array}$ & $\begin{array}{l}\text { An application program for building } \\
\text { vector diagrams }\end{array}$ \\
\hline
\end{tabular}

The beginning is the process of preparing, making and implementing decisions on the need for anti-crisis management in the system of ensuring the financial security of the enterprise. It can be implemented by iteratively approaching the necessary results and contain several stages.

First, in order to achieve our goal, we need to build a context-high-level diagram of the A-0 functional model of IDEF0 application of anti-crisis management in the process of ensuring the financial security of the enterprise. To do this, according to the source data, it is necessary to form a hierarchy of blocks of the functional model IDEF0 and a complex diagram of the model.

\section{Data}

In scientific and practical literature, mathematics and economists, they have successfully built a context-high-level diagram A-0 for the functional model IDEF0 and at least one level of its decomposition. But in order to detail our research and better reflect the process of applying anti-crisis management in the system of ensuring financial security of the enterprise, we decided to form not one such level, but two.

So, we will build a tree of nodes, a list of functions and objects with the corresponding explanations will become the initial basis for their creation (Figure 1). 


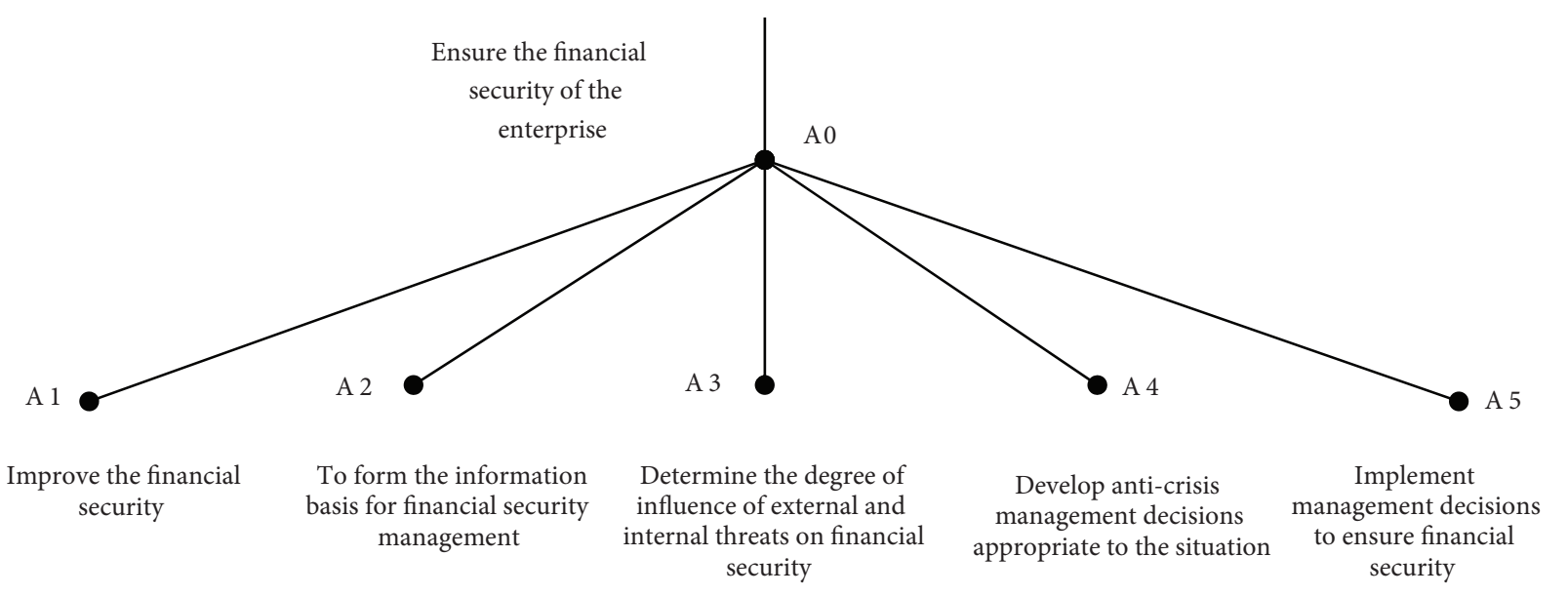

Figure 1. The hierarchy of blocks of the functional model IDEF0 application of anti-crisis management in the process of ensuring the financial security of the enterprise (source: developed by author)

Note that each block in the diagrams of the IDEF0 functional model carries out the process of converting inputs to outputs through certain mechanisms. For our task, it's enough to just talk about the transformation of information objects and flows.

In general, the information that is used in the process of preparing, adopting and implementing crisis management in the process of ensuring the financial security of the enterprise should be divided into: restrictive, descriptive and guiding.

The entire system we simulate is denoted by block A- 0 . In accordance with this, all inputs, outputs, controls and mechanisms will be connected to the unit by green arrows and codes of Figure 2.

In Figure 2 there are several mathematical notations that cover the main task - to ensure the financial security of the enterprise through the application of anti-crisis management. So, the input is $\mathrm{I} n(n=1,2)$, the control is $\mathrm{C} n(n=$ $1,2,3)$, the output is $\mathrm{O} n(n=1,2)$, the mechanism is $\mathrm{M} n$ $(n=1,2,3)$

It is necessary to consider in more detail each object that is indicated by arrows on the context diagram A- 0 we constructed for the functional model IDEF0 of applying anti-crisis management in the process of ensuring the financial security of the enterprise.

To begin, consider the list of functions of control objects (Control) in diagram A-0 of the functional model IDEF0:

$\mathrm{C} 1$ - Legislation and regulatory documents. This type of management objects relates to restrictive and governing information, respectively. This may include the current legislative framework governing the financial activities of enterprises, regulates security issues (including financial), characterizes the application of anti-crisis management at the legislative level, and the like. In addition, the structure of this management object includes internal regulatory documents that directly or even indirectly affect the issues of ensuring financial security and counteracting the financial crisis at the enterprise;

C2 - Models. This type of control objects on our diagram A-0 functional model IDEF0 refers to descriptive information. This may include the model proposed by Kh. Mandzinovska et al. (2016): model of the assessing the level of financial security, in which it is necessary to apply anti-crisis management; model proposed by O. Sylkin et al. (2018): hierarchy model the influence of internal and external threats on the financial security of enterprises.

C3 - Information from interested organizations and individuals. We assign this type of object to management information. This can include information (comments, recommendations, questions, ideas) coming from other enterprises and high-order facilities (feedback). This information has the aim, in processed form, to aim at improving the process of applying anti-crisis management in the system of ensuring the financial security of the enterprise.

In addition to the control objects, we will also consider the list of function of inputs (Input), which we indicated on the constructed diagram A- 0 of the functional model IDEF0:

I1 - Financial and material resources. This type of resource, which is used as one of the inputs in the diagram we constructed, refers to statistical information. These include both the funds available to the enterprise both on a permanent and temporary basis, and the means and objects of labor form the basis of material elements;

I2 - Information content to ensure financial security. Refers to descriptive information. The results obtained by the enterprise management of the process of forming the information content of anti-crisis management occupy an important place to ensure financial security. This process is recommended to be carried out before the direct process of ensuring the financial security of the enterprise, but the option of simultaneous action is also possible. 


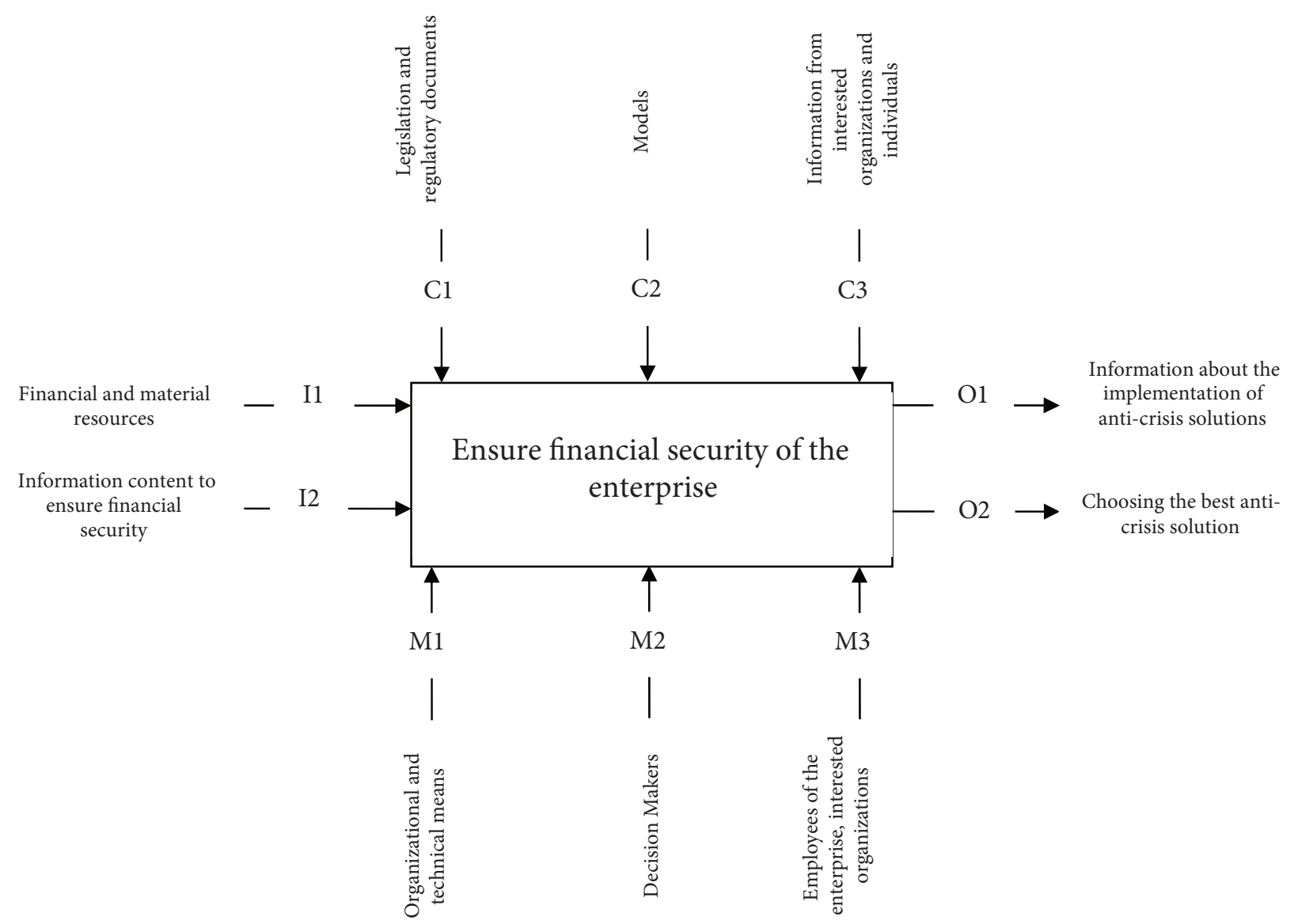

Figure 2. Complex diagram of the IDEF0 model of anti-crisis management in the process of ensuring the financial security of the enterprise (source: developed by author)

In addition, we consider the above-mentioned functions of mechanisms (Mechanism) in the constructed diagram A- 0 of the functional model IDEF0:

M1 - Organizational and technical means. The mechanism is a combination of a different number of ways and means of influencing personnel. In addition, we include personal computer equipment, software, various types of stationery and other technical means that have one or another impact on the process of counteracting crisis phenomena and ensuring the financial security of the enterprise;

M2 - Decisions Makers. It stands for "decision maker", that is, we take the company's management here, directly make a decisive decision and is responsible for the level of financial security;

M3 - Employees of the enterprise, interested organizations. Employees of the financial (financial and economic) service, the financial department and other personnel who are involved in the process of applying the anti-crisiss management and ensuring the financial security of the enterprise is an integral part of the mechanism. We will also include here organizations and employees of executive bodies that were involved from outside.
After reviewing the input functions, a logical step is to consider the list of output functions (Output) in the diagram A- 0 of the functional model IDEF0 that we constructed:

O1 - Information about the implementation of anticrisis solutions. After carrying out all the actions to ensure financial security at the exit, we get information that will contain all the necessary data on the implementation of anti-crisis measures and will serve as the main basis for other processes (for example, creating specific reports, etc.);

$\mathrm{O} 2$ - Choosing the best anti-crisis solution. In order to effectively apply anti-crisis measures, at the exit we get the best options for choosing the optimal anti-crisis solution.

\section{Results and discussions}

Many scientists have investigated and used the IDEF0 model in their research such as T. Entringer et al. (2019) and G. R. Waissi et al. (2015) however, this model has not been used to model the process of applying anti-crisis management in the context of ensuring the financial security of an enterprise.

As already noted above, we aim to significantly expand the decomposition of the context diagram of the IDEF0 
functional model in the field of safety-free and present two levels.

In Figure 3 decompositions of the first of two levels of the context diagram of the functional model IDEF0 of the application of anti-crisis management in the process of ensuring the financial security of the enterprise are given.

As can be seen from Figure 3, the decomposition of the first level of the context diagram of the IDEF0 functional model of the application of anti-crisis management in the process of ensuring the financial security of the enterprise consists of five blocks reflecting the provision of this type of security from the highest level of management. In the future, the second level will allow to detail an individual of the blocks shown in Figure 3.

Based on the decomposition we constructed in Figure 3 , we should substantively consider the list of functions that are depicted in blocks on the model diagram:

A1 - Improve the financial security. The process of ensuring financial security is very important and requires the involvement of a large number of resources and funds. During the period of crisis development, the enterprise no longer has such a quantity of resources and means, therefore, ensuring security becomes an extremely difficult task. In such a period, it is necessary to apply anti-crisis management, which should correspond to the current state of the enterprise, its capabilities, etc. This unit provides for the application of anti-crisis management in the process of ensuring the financial security of the enterprise and the collection, synthesis and analysis of information that is necessary and relevant. On its basis, solutions are developed to counter threats and crises at the enterprise. The results of work at this stage are the achievement of the objectives in the application of anti-crisis management in the process of ensuring the financial security of the enterprise in a timely manner within the allocated resources. Throughout the stage, the person who will make the decision must take into account the feedback and produce directives for managing subprocesses. The organization, information and resource support at this stage is very important, the whole process will depend on this.

A2 - Form the information basis for financial security management. Information about the past and the current level of financial security of the enterprise is collected, accumulated and calculated. In addition, the level of economic security as a whole should be calculated, since financial security is its key component. It also includes information on the operating environment of a given enterprise, determines the place and role of the studied business entity among other enterprises and objects of a better order, and identifies external and internal threats to the financial security of the enterprise. The collected information is filtered (resource, legal, social) in order to obtain only the most complete and high-quality information. The results of this stage will be presented in the form of a generalization and analysis of the information received, it allows us to further determine the key external and internal threats, their impact on the financial security of the enterprise.

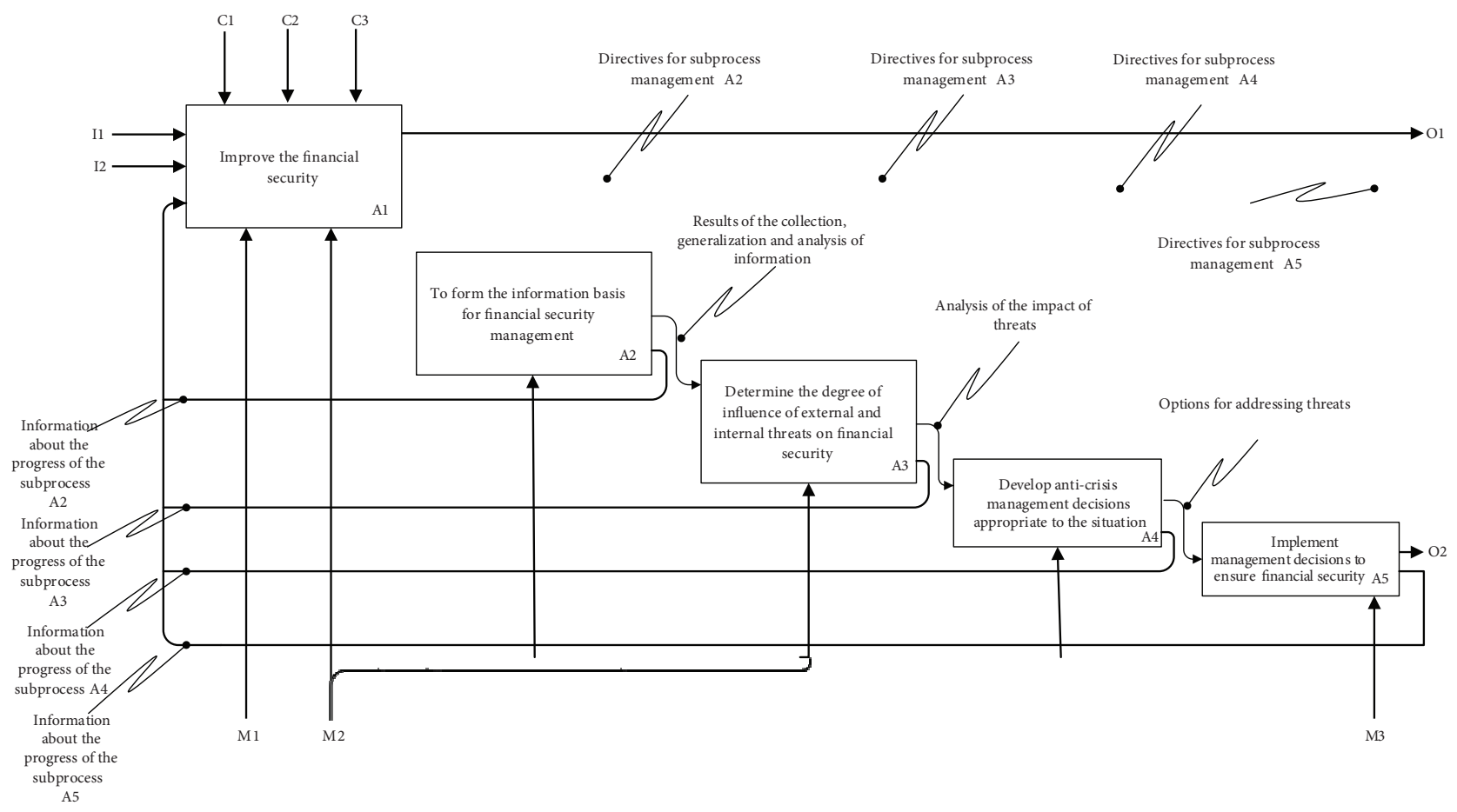

Figure 3. Decomposition of the first level of the context diagram of the IDEF0 model of the application of anti-crisis management in the process of ensuring the financial security of the enterprise (source: developed by author) 
A3 - Determine the degree of influence of external and internal threats on financial security. The key external and internal threats to the financial security of the enterprise that can lead to crisis development are identified. Their detailed analysis and hierarchical ordering of impact is carried out. The result of work at this stage is the analysis of the impact of threats, consists in ranking external and internal threats by the degree of influence on the process under study. Countering these threats should become the basis of anti-crisis management in the process of ensuring the financial security of the enterprise.

A4 - Develop the anti-crisis management decisions appropriate to the situation. Based on the data obtained in the previous step, as well as using any other information, the best way to solve the tasks is made. Synergy, personal experience of a person, making decisions and analysis methods, which the leading specialists of the enterprise possess, make it possible to fully take into account all aspects of the problem being solved. The result of work at this stage will be the choice of a strategy and measures to counter threats.

A5 - Implement management decisions to ensure financial security. The process of implementing anti-crisis management is a large-scale project, which consists in bringing the tasks to the performers, providing them with all the necessary resources and means, choosing rational working methods, explaining to the employees of the enterprise the decisions made and their role in implementing these decisions, and implementing appropriate incentives for the performers. It should always be remembered that this stage is very fragile, since the process of implementing any managerial decisions due to certain circumstances may require the introduction of tactical and operational adjustments and changes to the already adopted development strategy of the enterprise. The main results of work at this stage should be the formation of conditions for the effective work of performers. If the anti-crisis measures taken give positive results, this becomes the basis for adjusting activities to ensure the economic security of the enterprise.

Separately, intermediate inputs, outputs, control mechanisms, which can be seen as arrows on the constructed diagram of the IDEF0 functional model, should be characterized. The list of intermediate inputs (controls) and outputs are indicated by arrows on the diagram of the IDEF0 model of applying anti-crisis management in the process of ensuring the financial security of the enterprise:

- directives for subprocess management A2, A3, A4, A5 - these are the results of decision-making by the decision-maker at the enterprise;

- "Information about the progress of the subprocess A2, A3, A4, A5" - this kind of information comes from each subprocess of anti-crisis management in the process of ensuring the financial security of the enterprise. On its basis, a decision is made to terminate the subprocess and move on to the next;
- information about the progress of the subprocess A2 - the collection, processing, synthesis and analysis of information in the application of anti-crisis management, which provides for documenting all the results of such a process with a view to its further application through mathematical methods;

- information about the progress of subprocess A3 calculations of determining the priority effects of external and internal threats to the financial security of the enterprise using selected mathematical methods;

- information about the progress of the subprocess A4 - a document adopted in the prescribed manner contains goal setting, a list of means and methods for achieving them;

- information about the progress of the subprocess A5 - involves the inculcation of appropriate mechanisms at the enterprise administration level (higher order facilities or public authorities), as well as appropriate legal and financial support.

There are many studies on the formation of the financial security system of an enterprise. For example, V. Delas et al. (2015), tried to build the System of the company financial security provision, but our model differs by a mathematical approach through the use of the IDEF0 model, which consists of several levels of decomposition and covers a wide aspect of the financial security system.

There were studies of anti-crisis management and ways to build the appropriate algorithm in M. Nurmaganbetova et al. (2017), however, we offer a different approach to the consideration of anti-crisis management, which includes interaction and constant informational support of each stage in the developed model.

M. Soltysik (2014) presented the structure of the enterprise crisis management system and detailed its components, so we propose to consider the crisis management system through its key stages, which are presented in our diagram.

In contrast to the proposed T. Ganushchak (2017) structural logical scheme of the procedure of the analysis of the financial safety of the enterprise, we detail each stage of the financial security assessment thanks to our diagram.

As we noted earlier, in addition to constructing the decomposition of the first level, we built the second level of the context diagram of the functional model IDEF0 of applying anti-crisis management in the process of ensuring the financial security of the enterprise (Figure 4).

To demonstrate the decomposition of the second level, we chose the block of stage A3 - Determine the degree of influence of external and internal threats on financial security.

Based on the decomposition of the second level that we constructed in Figure 4, we should substantively consider the list of functions that are depicted in blocks on the model diagram: 
A31 - Manage the determination of the degree of influence of external and internal threats on financial security. The results of the collection, synthesis and analysis of information will allow us to begin the process of determining the degree of influence of external and internal threats on the financial security of the enterprise. Here, it is also very important that, during the whole stage, a person makes decisions, takes into account feedback and produces directives for managing subprocesses.

A32 - Assess the degree of influence of external and internal threats. At this stage, it is necessary to conduct a thorough assessment of the identified external and internal threats with a view to identifying only the most influential and those who present a real threat to the enterprise today.

A33 - Process threat assessment results. Through technical means, the decision maker provides a list of identified external and internal threats for expert assessment in order to determine the final list of threats that are currently the most dangerous for the enterprise.

A34 - Coordinate the results of peer review. A final list of external and internal threats to the financial security of the enterprise is being formed and agreed upon.

A35 - Rank external and internal threats by impact. The final stage of the decomposition of the second level, which involves the construction of a model of the hierarchy of impact, was discussed in more detail and practically in the next section.

Information on the progress of a particular process of decomposition of the second level of the IDEF0 functional model of applying anti-crisis management in the process of ensuring the financial security of the enterprise should also be characterized:

- information about the progress of the A32 process is information that includes the data of the process of assessing the degree of influence of external and internal threats, and its results, respectively;

- information about the progress of the process A33 - a document containing conclusions on the processing of the results of the assessment of the degree of influence of threats;

- information about the progress of the process A34 includes information on the established list of threats that have the greatest impact on the enterprise;

- information about the progress of the process A35 contains data on the results of construction; building models of the hierarchy of the influence of external and internal threats.

In carrying out the characteristics of the established stages of the application of anti-crisis management in the process of ensuring the financial security of the enterprise, the stages of model building and the selection of evaluation criteria are intentionally not seen. The reason is that all this is carried out at almost all stages of the preparation, adoption and implementation of anti-crisis management decisions. For example, certain evaluative (generally different) criteria are used when ranking the external and internal threats to the financial security of the enterprise, and when choosing alternatives to a solution, and when determining the degree of its implementation and the like.

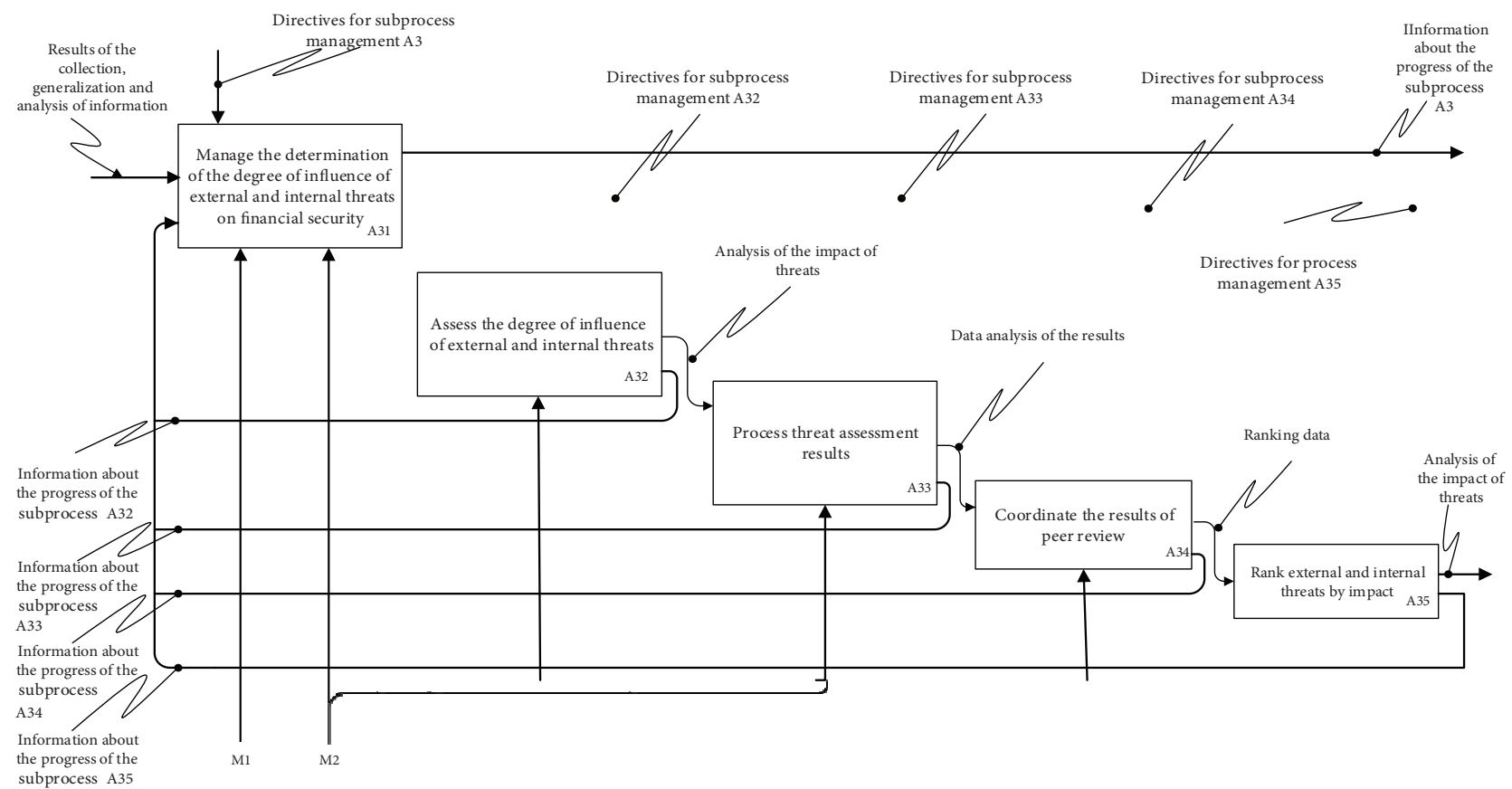

Figure 4. Decomposition of the second level of the context diagram of the IDEF0 model of the application of anti-crisis management in the process of ensuring the financial security of the enterprise (source: developed by author) 
In addition, it should also be noted that a clear sequential division of management activities into phases is very rare. The reason is that almost all stages for this type of activity can be carried out simply in parallel. It is not always possible to justify and solve the problem successfully and as openly as possible the first time. A change in the permissible limits of the previously formulated goals makes it possible to significantly increase the efficiency of solving the problem by using more effective means to achieve it. For a successful solution, it is necessary to carry out a repeating cycle of formulating the problem, choosing final goals, developing ways to achieve goals, evaluating their effectiveness, checking and clarifying the final goals, developing new solutions and the like. That is, there is always a possible return from any stage of decomposition of the first, second levels of the IDEF0 functional model to the previous ones.

The proposed decomposition of the first, second and third levels of the context diagram of the IDEF0 model of the application of anti-crisis management in the process of ensuring the financial security of the enterprise allows enterprises to better carry out their planning and development of financial and anti-crisis strategies in practice.

Of course, the study has its limitations. First of all, this concerns the fact that the proposed model was built with targeting for enterprises in Eastern Europe and therefore it cannot yet be called comprehensive.

In the future, we plan to expand the decomposition to the fourth level and concentrate on a specific area of entrepreneurial activity.

\section{Conclusions}

Having formed a methodological approach to the application of anti-crisis management in the financial security system of the enterprise, we made it possible for the enterprise adapt to a changing market environment, increase competitiveness and ensure the stability of financial and economic activities using the methodology of functional modelling and graphical description of processes (IDEF0).

Thus, the process of applying the anti-crisis management in the system of ensuring the financial security of the enterprise that we have examined is iterative in nature, which in turn means that during the work you should constantly show some flexibility when new factors arise and re-evaluate the results. In some cases, it may also be necessary to change the idea itself, which has become the basis.

We have built a context high-level diagram A-0 of the IDEF0 functional model for the application of anti-crisis management in the process of ensuring the financial security of the enterprise. A context diagram of the IDEF0 model of application of anti-crisis management in the process of ensuring the financial security of the enterprise includes an input, control, output, mechanism. As a result, a decomposition of the first level of the context diagram of the IDEF0 model of the application of anti-crisis management in the process of ensuring the financial security of the enterprise was formed, which includes, in addition to input, control, output and mechanism, information on the progress of subprocesses and directives for their regulation.

We made a decision to formed decompositions of the second level of the context diagram of the IDEF0 model of applying anti-crisis management in the process of ensuring the financial security of the enterprise. It is a detail of A3 decomposition of the first level - determining the degree of influence of external and internal threats on financial security.

\section{Author contributions}

The authors contributed equally.

\section{Disclosure statement}

The authors do not have any conflict of interest.

\section{References}

Adbulaziz A (2016) Formation of the organizational-economic mechanism of anti-crisis management of the enterprise. Thesis for the degree of candidate of economic sciences, Lugansk National Agrarian University, Kharkov, 196.

Arefieva A, Kuzenko T (2009) Economic foundations of the formation of financial security. Actual problems of the economy 1: 98-103.

Barton R (1993) The anti-crisis management. Oxford Press Publishers, Oxford, 428.

Delas V, Nosova E, Yafinovych O (2015) Financial security of enterprises. Procedia Economics and Finance 27 (2015): 248266. https://doi.org/10.1016/S2212-5671(15)00998-3

Ershova N (2009) Diagnostics in the system of crisis management of machine-building enterprises. The dissertation for the degree of candidate of economic sciences. Kharkov Polytechnic Institute. Kharkov http://www.kpi.kharkov.ua

Entringer T, Nascimento D, Ferreira A, Siqueira P, Boechat A, Cerchiaro I, Mendonça S, Ramos R (2019) Comparative analysis main methods business process modeling: literature review, applications and examples. IJAERS 6 (5). https://doi.org/10.22161/ijaers.6.5.15

Ganushchak T (2017) Dynamics of development of financial safety of the enterprise as a complex economic security of the state. Baltic Journal of Economic Studies 3 (4): 32-36. https:// doi.org/10.30525/2256-0742/2017-3-4-32-37

Gavrilenko V (2018) Methodology and organization of accounting and analytical support of anti-crisis enterprise management. Abstract of dissertation for the degree of candidate of economic sciences, specialty 08.00.04 - economics and enterprise management. Odessa National University of Economics. Odessa, 41.

Golovach K (2016) Formation of a anti-crisis management mechanism in agricultural enterprises. The dissertation for the degree of candidate of economic sciences, specialty 08.00.04economics and enterprise management. Zhytomyr National Agroecological University. Zhytomyr, 249. 
Hryhoruk P, Khrushch N, Grygoruk S (2019) Model for assessment of the financial security level of the enterprise based of the desirability scale. SHS Web Conference, vol. 65. https://doi.org/10.1051/shsconf/20196503005

Kartuzov E (2012) Definition of financial security of an enterprise: concept, content, value and functional aspects. Economics and enterprise management. Actual Problems of the Economy 8 (134): 172-181.

Lynenko A, Konyev V (2017) Assessment of financial security of enterprises association participants. Agricultural and Resource Economics: International Scientific E-Journal 3 (4): 85-95.

Malik A (2015) The formation of the mechanism of financial security management of the enterprise. Thesis for the degree of PhD. Khmelnitsky, 263.

Marchenko A (2014) Opportunities for improving the financial security of enterprises in the construction industry in modern conditions. Business-Inform 9 http://business-inform.net/ export_pdf/business-inform-2014-9_0-pages-157_161.pdf

Mandzinovska Kh, Shtangret A, Kotlyarevskyi Ya, Melnikov A (2016) Financial security of a machine-building enterprise: Methodical bases of formation and provision (monograph). Ukrainian Academy of Printing, Lviv, 226.

Nurmaganbetova M, Tarakbayeva E, Nakisheva M (2017) Developing the algorithm of crisis management in the system of crisis administration at the enterprise. Revista ESPACIOS 38: 3-14 https://www.revistaespacios.com/a17v38n62/ a17v38n62p03.pdf

Plastun A (2007) Development of the financial security system of business entities in the sphere of material production. Thesis for the degree of candidate of economic sciences. Ukrainian Academy of Banking of the National Bank of Ukraine, Sumy https://essuir.sumdu.edu.ua/bitstream/123456789/51464/1/ plastun_financial_safety.pdf

Pogrebnyak A (2016) Anti-crisis management mechanism at engineering enterprises. Thesis for the degree of candidate of economic sciences. National Technical University of Ukraine "Kiev Polytechnic Institute". Kiev, 234 pp.
Schwartz I (2008) The mechanism for ensuring the effectiveness of anti-crisis enterprise management. The dissertation for the degree of candidate of economic sciences, specialty 08.00.04economics and enterprise management (mechanical engineering). Khmelnitsky National University. Khmelnitsky, 25.

Smovkina A (2014) Financial security as a strategic component of the economic security of Ukraine. Industrial Economics and Organization of Production 3 (13)

http://economics.opu.ua/files/archive/2014/No3/30-36.pdf

Shary V (2006) Anti-crisis technologies as a mechanism for the implementation of public administration goals. The dissertation for the degree of candidate of science in public administration. National Academy of Public Administration under the President of Ukraine. Kiev http://academy.gov.ua/ NMKD/library_nadu/Avtoreferat/e4b7b2e4-b2bb-44e2-a95bfda31763bb02.pdf

Sylkin O, Shtangret A, Ogirko O, Melnikov A (2018) Assessing the financial security of the engineering enterprises as preconditions of application of anti-crisis management: practical aspect. Business and Economic Horizons 14 (4): 926-940. https://doi.org/10.15208/beh.2018.63

Soltysik M (2014) Crisis management system in the enterprise. Organization and Management 4 (164): 85-98.

Wu Y, Meng F (2019) Categorizing security for security management and information resource management. Journal of Strategic Security 11 (4): 72-84. https://doi.org/10.5038/1944-0472.11.4.1694

Waissi RG, Demir M, Humble EJ, Lev B (2015) Automation of strategy using IDEF0 - A proof of concept. Operations Research Perspectives 2: 106-113. https://doi.org/10.1016/j.orp.2015.05.001

Zhou B (2016) Enterprises treasury management strategy in post financial crisis era. Quality Technology and Quantitative Management 11 (2): 217-222. https://doi.org/10.1080/16843703.2014.11673338 